\title{
Clinical utility of ultrasound guidance for intra-articular knee injections: a review
}

This article was published in the following Dove Press journal:

Clinical Interventions in Aging

16 March 2012

Number of times this article has been viewed

\section{David J Berkoff' \\ Larry E Miller ${ }^{2,3}$ \\ Jon E Block ${ }^{3}$}

'Department of Orthopedics, University of North Carolina School of Medicine, Chapel Hill, NC; ${ }^{2}$ Miller Scientific Consulting Inc, Arden, NC; ${ }^{3}$ The Jon Block Group, San Francisco, CA, USA
Correspondence: Jon E Block

The Jon Block Group, 2210 Jackson

Street, Suite 40I, San Francisco,

CA 94115 , USA

Tel +l 4I5 7757947

Fax + I 4159280765

Email jonblock@jonblockgroup.com

\begin{abstract}
Intra-articular corticosteroid and hyaluronic acid injections provide short-term symptom amelioration for arthritic conditions involving structural damage or degenerative changes in the knee. Conventional palpation-guided anatomical injections frequently result in inaccurate needle placement into extra-articular tissue and adjacent structures. The purpose of this review was to determine the effect of ultrasound guidance on the accuracy of needle placement, clinical outcomes, and cost-effectiveness in comparison with anatomical landmarkguided intra-articular large joint injections, with particular emphasis on the knee. A total of 13 relevant studies were identified; five studied the knee, seven studied the shoulder, one used both the knee and shoulder, and none studied the hip. Ultrasound was used in seven studies; the remaining studies utilized air arthrography, fluoroscopy, magnetic resonance arthrography, or magnetic resonance imaging. Across all studies (using all imaging modalities and all joints), needle placement accuracy ranged from $63 \%$ to $100 \%$ with ultrasound and from $39 \%$ to $100 \%$ with conventional anatomical guidance. Imaging guidance improved the accuracy of intraarticular injections of the knee $(96.7 \%$ versus $81.0 \%, P<0.001)$ and shoulder $(97.3 \%$ versus $65.4 \%, P<0.001)$. In particular, ultrasound guidance of knee injections resulted in better accuracy than anatomical guidance $(95.8 \%$ versus $77.8 \%, P<0.001)$, yielding an odds ratio of 6.4 (95\% confidence interval 2.9-14). Ultrasound guidance notably improves injection accuracy in the target intra-articular joint space of large joints including the knee. The enhanced injection accuracy achieved with ultrasound needle guidance directly improves patient-reported clinical outcomes and cost-effectiveness.
\end{abstract}

Keywords: injection, intra-articular, knee, ultrasound

\section{Introduction}

Intra-articular injections of corticosteroids have been used for several decades in the management of inflammatory and degenerative joint conditions when first-line conservative therapies such as rest, ice, and anti-inflammatory medications fail to provide adequate symptom relief. Based in part on this long history of successful utilization coupled with the findings of several randomized controlled trials, consensus statements and meta-analyses have concluded that intra-articular corticosteroid injections provide short-term patient benefit and clinical efficacy for chronic knee pain. ${ }^{1-3}$ More recently, various injectable hyaluronic acid agents have become commercially available and have enjoyed widespread clinical acceptance as an effective treatment for knee osteoarthritis. These agents are indicated for the treatment of the pain associated with osteoarthritis of the knee in patients who have failed to respond adequately to conservative nonpharmacologic therapy and simple analgesics, eg, acetaminophen. 
Traditionally, intra-articular injections have been performed using anatomical landmarks to identify the correct trajectory for needle placement. However, different anatomical-guided injection techniques have yielded inconsistent intra-articular needle positioning due, in large part, to the fact that the physician cannot directly visualize the area of interest, and variations in anatomy are common. Incorrect needle placement has been partially attributed to variable clinical outcomes. ${ }^{4-10}$ Furthermore, inaccurate corticosteroid injections in the knee, for example, may result in post-injection pain, crystal synovitis, hemarthrosis, joint sepsis, and steroid articular cartilage atrophy, as well as systemic effects, such as fluid retention or exacerbation of hypertension or diabetes mellitus. ${ }^{1}$ Therefore, identification of methods and proper training to aid in correct needle placement during these procedures is warranted.

Various imaging modalities can be used to improve the accuracy of intra-articular injections, including fluoroscopy, computed tomography, and magnetic resonance imaging. However, musculoskeletal ultrasound is one of the most practical because it is rapid, safe, relatively inexpensive, emits no ionizing radiation, and can be performed in the outpatient clinical setting. ${ }^{11,12}$ Ultrasound utilizes high-frequency sound waves to visualize soft tissues and bony structures and is a frequently used imaging modality to diagnose musculoskeletal pathology or to aid with needle guidance during interventional procedures. Importantly, unlike fluoroscopy, ultrasound allows identification of vascular and nervous structures as well as demonstrating needle movement in real time to aid in needle positioning without the use of contrast medium. ${ }^{13}$ The purpose of this review was to determine the effect of ultrasound guidance on the accuracy of needle placement, clinical outcomes, and cost-effectiveness in comparison with anatomical landmark-guided intra-articular large joint injections, with particular emphasis on the knee.

\section{Materials and methods}

The peer-reviewed literature was searched using Medline and relevant bibliographies published in English language journals through December 31, 2011 that compared the accuracy of intra-articular large joint injections with imaging guidance versus conventional anatomical guidance. The initial search yielded 4971 publications related to joint injections. After screening titles and abstracts and excluding irrelevant articles, 47 articles were considered for inclusion into this review. Full-text manuscripts of these studies were retrieved and reviewed. Of the 47 articles screened, 13 studies met the criteria for inclusion in this review.
All studies of large joints (ie, knee, hip, and shoulder) utilizing any imaging modality to aid with needle placement were analyzed. The imaging-guided group was further subdivided by ultrasound or other imaging modalities. Injection accuracy rates between groups were analyzed with Fisher's Exact test and odds ratios with $95 \%$ confidence intervals were calculated. Clinical outcome and cost-effectiveness data were summarized in a narrative review due to inconsistent reporting that made objective data analysis impractical.

\section{Results \\ Accuracy of ultrasound-guided intra-articular injections}

A total of 13 studies were identified that met the entry criteria; ${ }^{14-26}$ five studied the knee, ${ }^{15,17,20,21,26}$ seven studied the shoulder, ${ }^{14,16,18,22-25}$ and one studied both the knee and shoulder. ${ }^{19}$ No comparative studies of the hip were identified. Ultrasound was used in seven studies, ${ }^{15,19-21,23,25,26}$ and the remaining studies utilized air arthrography, ${ }^{17}$ fluoroscopy, ${ }^{14,16,24}$ magnetic resonance arthrography, ${ }^{18}$ or magnetic resonance imaging ${ }^{22}$ (Table 1). Across all studies (using all imaging modalities and all joints), needle placement accuracy ranged from $63 \%$ to $100 \%$ with ultrasound and from $39 \%$ to $100 \%$ with conventional anatomical guidance (Table 2). Imaging guidance improved the accuracy of intra-articular injections of the knee $(96.7 \%$ versus $81.0 \%, P<0.001)$ and shoulder $(97.3 \%$ versus $65.4 \%, P<0.001$, Table 3$)$. In particular, ultrasound guidance of knee injections resulted in better accuracy than did anatomical guidance $(95.8 \%$ versus $77.8 \%, P<0.001)$. The five studies comparing the accuracy of ultrasound guidance with anatomical guidance of intra-articular knee injections demonstrated superior accuracy with ultrasound, with an odds ratio of 6.4 (95\% confidence interval 2.9-14, Figure 1).

\section{Clinical outcome of ultrasound-guided intra-articular injections}

Despite the evidence for improved accuracy of intra-articular injections using ultrasound guidance, some researchers have questioned whether improved injection accuracy translates directly into better clinical outcomes. ${ }^{19,27}$ Jones et al ${ }^{4}$ reported that clinical improvement was reported in 52\% (28 of 54) of subjects with correctly placed intra-articular corticosteroid injections, but in only $23 \%$ (seven of 30 ) with incorrectly placed extra-articular injections. This finding was corroborated by Cunnington et al who demonstrated that accurate intra-articular injections improve joint 


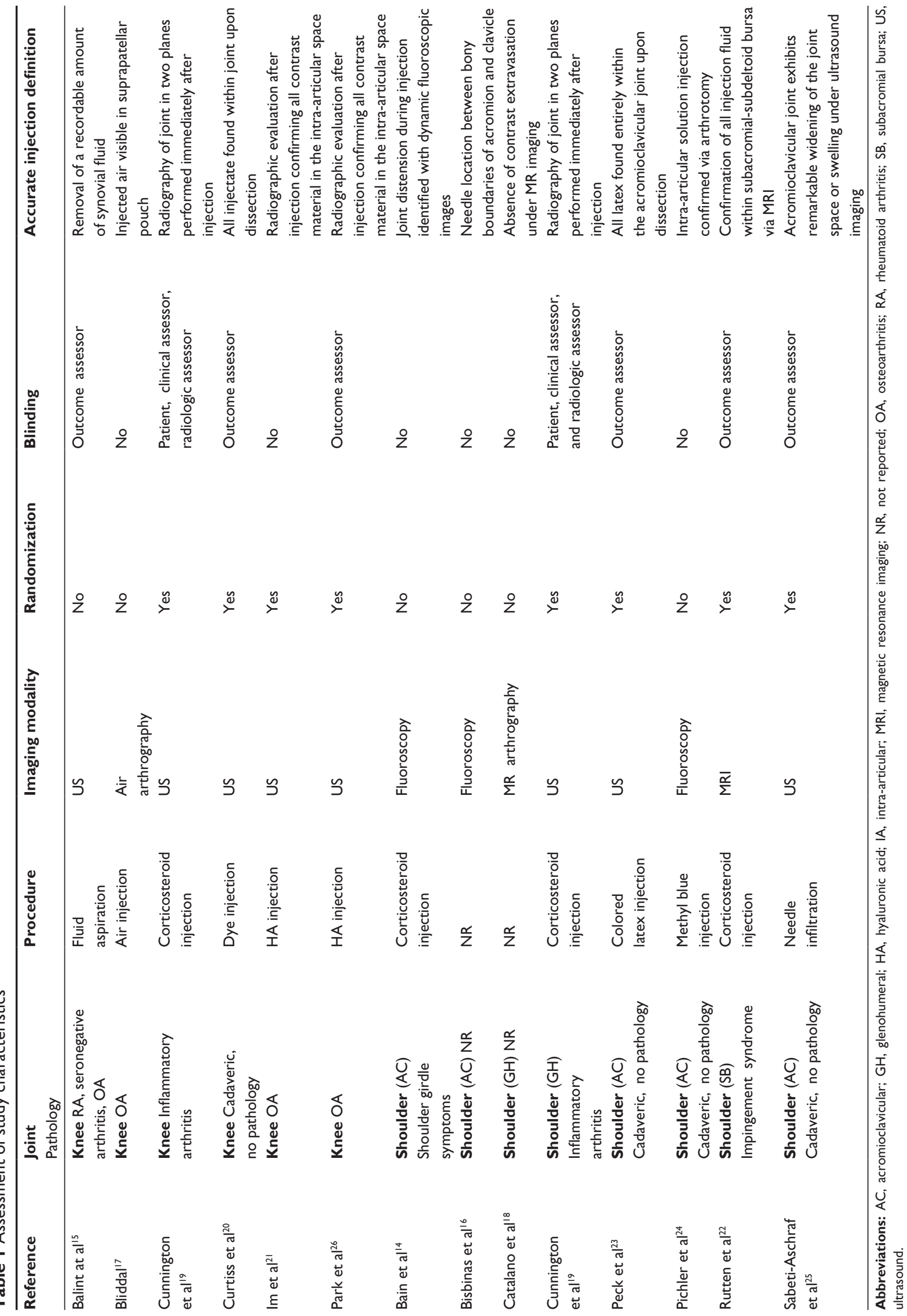


Table 2 Controlled studies of imaging-guided intra-articular knee and shoulder injection accuracy

\begin{tabular}{|c|c|c|c|}
\hline \multirow[t]{2}{*}{ Reference } & \multirow{2}{*}{$\begin{array}{l}\text { Joint } \\
\text { Pathology }\end{array}$} & \multicolumn{2}{|c|}{ Needle placement accuracy (\%) } \\
\hline & & Image-guided & No imaging \\
\hline Balint et al ${ }^{15}$ & $\begin{array}{l}\text { Knee RA, seronegative } \\
\text { arthritis, OA }\end{array}$ & 94.7 (18 of 19) & $40.0(4$ of 10$)$ \\
\hline Bliddal ${ }^{17}$ & Knee OA & $100(56$ of 56$)$ & 91.1 (5I of 56) \\
\hline Cunnington et $\mathrm{al}^{19}$ & Knee Inflammatory arthritis & 91.4 (32 of 35$)$ & $81.8(27$ of 33$)$ \\
\hline Curtiss et $\mathrm{al}^{20}$ & Knee Cadaveric, no pathology & $100(40$ of 40$)$ & $77.5(31$ of 40$)$ \\
\hline $\operatorname{Im}$ et $\mathrm{a}^{21}$ & Knee OA & $95.6(43$ of 45$)$ & $77.3(34$ of 44$)$ \\
\hline Park et $\mathrm{a}^{26}$ & Knee OA & $96.0(48$ of 50$)$ & 83.7 (4I of 49$)$ \\
\hline Bain et $\mathrm{al}^{14}$ & $\begin{array}{l}\text { Shoulder (AC) Shoulder girdle } \\
\text { symptoms }\end{array}$ & $100(44$ of 44$)$ & $54.5(24$ of 44$)$ \\
\hline Bisbinas et $\mathrm{al}^{16}$ & Shoulder (AC) NR & $100(66$ of 66$)$ & $39.4(26$ of 66$)$ \\
\hline Catalano et al ${ }^{18}$ & Shoulder (GH) NR & $100(147$ of 147$)$ & $85.0(125$ of 147$)$ \\
\hline Cunnington et $\mathrm{al}^{19}$ & $\begin{array}{l}\text { Shoulder (GH) Inflammatory } \\
\text { arthritis }\end{array}$ & $63.2(12$ of 19$)$ & $40.0(8$ of 20$)$ \\
\hline Peck et a ${ }^{23}$ & $\begin{array}{l}\text { Shoulder (AC) Cadaveric, } \\
\text { no pathology }\end{array}$ & $100(10$ of 10$)$ & $40.0(4$ of 10$)$ \\
\hline Pichler et $\mathrm{al}^{24}$ & $\begin{array}{l}\text { Shoulder (AC) Cadaveric, } \\
\text { no pathology }\end{array}$ & $100(20$ of 20$)$ & $56.6(43$ of 76$)$ \\
\hline Rutten et $\mathrm{a}^{22}$ & $\begin{array}{l}\text { Shoulder (SB) Impingement } \\
\text { syndrome }\end{array}$ & $100(10$ of 10$)$ & $100(10$ of 10$)$ \\
\hline Sabeti-Aschraf et $\mathrm{a}^{25}$ & $\begin{array}{l}\text { Shoulder (AC) Cadaveric, } \\
\text { no pathology }\end{array}$ & $95.0(57$ of 60$)$ & $71.7(43$ of 60$)$ \\
\hline
\end{tabular}

Abbreviations: AC, acromioclavicular; GH, glenohumeral; OA, osteoarthritis; RA, rheumatoid arthritis; SB, subacromial bursa.

function significantly at 6 weeks compared with inaccurate injections. ${ }^{19}$ Furthermore, injections guided by ultrasound were associated with better self-reported health-related quality of life at 6 weeks. ${ }^{19}$

In a randomized controlled trial of 148 painful joints (62 of 148, 41.9\% knee) comparing ultrasound-guided and anatomical-guided corticosteroid injections in rheumatoid arthritis $(n=100)$ and osteoarthritis $(n=48)$, Sibbitt et $\mathrm{a}^{28}$ reported that ultrasound guidance resulted in a $43 \%$ reduction in procedural pain $(P<0.001)$, a $59 \%$ reduction in absolute pain scores at the 2 -week outcome $(P<0.001)$, a $75 \%$ reduction in significant pain (defined as visual analog score $\geq 5 \mathrm{~cm} ; P<0001)$, a $26 \%$ increase in the responder rate (defined as reduction in visual analog score $\geq 50 \%$ from

Table 3 Needle placement accuracy of controlled studies of imageguided intra-articular knee and shoulder injection accuracy

\begin{tabular}{llll}
\hline Joint & \multicolumn{2}{c}{ Needle placement accuracy $(\%)$} & P value* \\
\cline { 2 - 3 } & Image-guided & No imaging & \\
\hline Knee & & & \\
All imaging modalities & $96.7(237$ of 245$)$ & $81.0(188$ of 232$)$ & $<0.00$ I \\
US only & $95.8($ I8I of I89) & $77.8(137$ of I76) & $<0.00$ I \\
Shoulder & & & \\
All imaging modalities & $97.3(366$ of 376$)$ & $65.4(283$ of 433$)$ & $<0.00$ I \\
US only & $88.8(79$ of 89$)$ & $61.1(55$ of 90$)$ & $<0.001$ \\
\hline
\end{tabular}

Note: *Fisher's Exact test.

Abbreviation: US, ultrasound. baseline; $P<0.01$ ), and a $62 \%$ reduction in the nonresponder rate (defined as reduction in visual analog score $<50 \%$ from baseline; $P<0.01$ ). Ultrasound also increased detection of effusion by $200 \%$ and volume of aspirated fluid by $337 \%$. A previously unappreciated finding was the marked difference in procedural pain favoring ultrasound guidance. Although the causes of this significant beneficial reduction in procedural pain are uncertain, the authors speculated that better control and direction of the needle away from painsensitive structures during introduction of the needle into the intra-articular space are the most likely explanations. ${ }^{29}$ Indeed, a randomized controlled trial demonstrated that procedural pain during needle procedures is a surrogate measure for direct needle trauma to patient tissues, with better needle control being significantly associated with less intra-articular bleeding, less tissue trauma, reduced pain, and less bruising. ${ }^{30}$

Sibbitt et al also conducted a randomized controlled trial of intra-articular corticosteroid injections for inflammatory arthritis. ${ }^{31}$ Two hundred and forty-four joints (85 of 244, $34.8 \%$ knee) were randomized to injection with conventional anatomical guidance $(\mathrm{n}=120)$ or ultrasound guidance $(\mathrm{n}=124)$. Compared with anatomical guidance, ultrasound guidance reduced injection pain by $81 \%(P<0.001)$, lowered 6-month pain scores by $35 \%(P<0.02)$, and increased therapeutic duration by $32 \%(P=0.01)$. 


\begin{tabular}{|c|c|c|c|c|c|c|c|}
\hline \multirow[t]{2}{*}{ Study name } & \multicolumn{3}{|c|}{ Study statistics } & \multicolumn{4}{|c|}{ Odds ratio and $95 \% \mathrm{Cl}$} \\
\hline & $\begin{array}{l}\text { Odds } \\
\text { ratio }\end{array}$ & $\begin{array}{c}\text { Lower } \\
\text { limit }\end{array}$ & $\begin{array}{l}\text { Upper } \\
\text { limit }\end{array}$ & & & & \\
\hline Balint et al ${ }^{15}$ & 27 & 2.0 & $>100$ & & 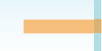 & 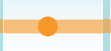 & 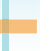 \\
\hline Cunnington et al ${ }^{19}$ & 2.4 & 0.5 & 13 & 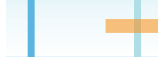 & 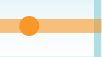 & 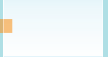 & \\
\hline Curtiss et $\mathrm{al}^{20}$ & Inf & 2.0 & Inf & & - & & 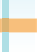 \\
\hline Im et $\mathrm{al}^{21}$ & 6.3 & 1.2 & 45 & & 0 & 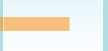 & \\
\hline Park et $a^{26}$ & 4.7 & 0.9 & 23 & & 0 & 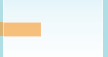 & \\
\hline Overall & 6.4 & 2.9 & 14 & & $\bullet$ & 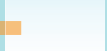 & \\
\hline
\end{tabular}

Figure I Accuracy of ultrasound guidance for intra-articular knee injections: forest plot of controlled studies.

The same research group recently reported the findings of a controlled trial of 94 noneffusive knees with osteoarthritis randomly allocated to intra-articular corticosteroid treatment with either ultrasound guidance or anatomical guidance. ${ }^{32}$ Ultrasound guidance yielded $48 \%$ less procedural pain $(P<0.001)$, a $36 \%$ increase in therapeutic duration $(P=0.01)$, and $42 \%$ less knee pain at 2 months $(P<0.03)$ but no difference at 6 months.

Finally, Sibbitt et al conducted a randomized controlled trial comparing the clinical outcome of ultrasound-guided $(n=42)$ or anatomical-guided $(n=22)$ arthrocentesis and intra-articular corticosteroid injection. ${ }^{33}$ Patients who received ultrasound-guided injections reported $48 \%$ less procedural pain $(P=0.001)$ and $46 \%$ less pain at 2 weeks $(P=0.03)$.

\section{Cost-effectiveness of ultrasound-guided intra-articular injections}

The limited evidence suggests that improved injection accuracy and correspondingly better clinical outcomes achieved with ultrasound guidance are also cost-effective. In their large, randomized, controlled trial in inflammatory arthritis, Sibbitt et $\mathrm{al}^{31}$ found that ultrasound injection guidance modestly reduced the cost per patient per year by $8 \%(\$ 7)$ relative to anatomical guidance. More importantly, ultrasound guidance significantly reduced the cost per responder per year by $33 \%$ (\$64; $P<0.001)$. In their follow-up study in osteoarthritis, Sibbitt et $\mathrm{al}^{32}$ reported that ultrasound guidance reduces the costs of treating a hospital outpatient by $13 \%$ (\$17), particularly in responders (reduction of $58 \%$ or $\$ 224$ ).

\section{Discussion}

Intra-articular knee injections are commonly performed by orthopedic surgeons and rheumatologists, and as the role of general practitioners in chronic disease management expands, joint injections are now frequently being performed in the primary care setting. This trend underscores the necessity to standardize the procedure to assure patient comfort and safety by employing the most accurate injection techniques possible. Numerous imaging modalities may be used to aid the clinician in identifying the correct trajectory for intraarticular diagnostic and/or therapeutic injections including ultrasound, fluoroscopy, computed tomography, and magnetic resonance imaging. However, ultrasound represents one of the most practical options because it is safe, quick, comparatively inexpensive, and emits no radiation. Although numerous studies have reported the accuracy of intra-articular joint injections using imaging or anatomical guidance, few controlled studies comparing the accuracy of these methods have been performed. The results of the current analysis demonstrate that use of imaging guidance improves the accuracy of intra-articular injection in large joints including the knee. Furthermore, the use of ultrasound guidance specifically at the knee greatly increases the likelihood of correct needle placement. These findings confirm and extend similar conclusions reached by Daley et $\mathrm{al}^{34}$ in their systematic review of injection accuracy.

Relative to corticosteroids that act to quell the inflammatory reaction in intra-articular and peri-articular structures, injection accuracy may be particularly important for hyaluronic acid because this therapeutic agent directly confers a number of protective properties to joint fluid, including shock absorption, traumatic energy dissipation, protective coating of the articular surface, and lubrication. A large meta-analysis by the Cochrane Collaboration found that hyaluronic acid viscosupplementation provides beneficial effects on knee pain, function, and patient global assessment comparable with systemic forms of active 
intervention, and that hyaluronic acid products have more prolonged effects than intra-articular corticosteroids. ${ }^{35}$ Notably, Bannuru et $\mathrm{al}^{36}$ demonstrated the time-varying effects of both agents for knee pain. Specifically, from baseline to 4 weeks, intra-articular corticosteroids are relatively more effective for pain relief than intra-articular hyaluronic acid. However, by week 4 , both interventions show similar efficacy, with hyaluronic acid administration reaching peak effectiveness at 8 weeks and exerting a residual detectable effect at 24 weeks. The use of ultrasound guidance with hyaluronic acid injection has potential to improve clinical outcomes further, although prospective trials are required to confirm this theory.

We also noted that accurate intra-articular injections with ultrasound guidance result in improved clinical outcomes, and preliminary evidence suggests that these patient benefits result in long-term health care savings. On balance, the assessment of cost-effectiveness of ultrasoundguided injections in these studies is likely to be somewhat overestimated by failing to account for the initial equipment costs, equipment maintenance costs, costs associated with staff training, and the additional procedural time required for ultrasound guidance, all of which are factors that may partially explain why ultrasound remains infrequently utilized. In the US, only one in five rheumatologists regularly utilizes musculoskeletal ultrasound in their practice, although three out of four agree that it should be a standard clinical tool for diagnosis, injection guidance, and gauging treatment response. ${ }^{37}$

Limitations of this review include heterogeneity of the evaluation methods, lack of consistent outcome blinding methods, and a relatively small number of relevant studies identified. Of the five comparative studies of ultrasound versus anatomical injection guidance at the knee, two utilized patients with osteoarthritis, one used inflammatory arthritis, one used various forms of arthritis, and one used cadavers. The procedural methods used in these comparative studies also varied, with two studies using hyaluronic acid injection while fluid aspiration, corticosteroid injection, and dye injection in cadavers were used in one study each. Studies were inconsistently blinded, which may yield biased results. Lastly, the results of this systematic review lack robustness and, with the inclusion of future trials, the reported accuracy rates may be quite sensitive to change.

Overall, the use of imaging guidance, in particular ultrasound, improves the accuracy of intra-articular injection in large joints, including the knee. Furthermore, accurate ultrasound-guided intra-articular knee injections improve clinical outcomes and lower health care costs.

\section{Acknowledgment}

We thank Randy Asher for his assistance with graphical illustrations.

\section{Disclosure}

Smith and Nephew Inc (Durham, NC) provided financial support for development of this manuscript.

\section{References}

1. Bellamy N, Campbell J, Robinson V, Gee T, Bourne R, Wells G. Intraarticular corticosteroid for treatment of osteoarthritis of the knee. Cochrane Database Syst Rev. 2006;2:CD005328.

2. Bannuru RR, Natov NS, Obadan IE, Price LL, Schmid CH, McAlindonTE. Therapeutic trajectory of hyaluronic acid versus corticosteroids in the treatment of knee osteoarthritis: a systematic review and meta-analysis. Arthritis Rheum. 2009;61(12):1704-1711.

3. Zhang W, Nuki G, Moskowitz RW, et al. OARSI recommendations for the management of hip and knee osteoarthritis: part III: changes in evidence following systematic cumulative update of research published through January 2009. Osteoarthritis Cartilage. 2010;18(4):476-499.

4. Jones A, Regan M, Ledingham J, Pattrick M, Manhire A, Doherty M. Importance of placement of intra-articular steroid injections. $B M J$. 1993;307(6915):1329-1330.

5. Jackson DW, Evans NA, Thomas BM. Accuracy of needle placement into the intra-articular space of the knee. J Bone Joint Surg Am. 2002;84A(9):1522-1527.

6. Eustace JA, Brophy DP, Gibney RP, Bresnihan B, FitzGerald O. Comparison of the accuracy of steroid placement with clinical outcome in patients with shoulder symptoms. Ann Rheum Dis. 1997;56(1):59-63.

7. Partington PF, Broome GH. Diagnostic injection around the shoulder: hit and miss? A cadaveric study of injection accuracy. J Shoulder Elbow Surg. 1998;7(2):147-150.

8. Helm AT, Higgins G, Rajkumar P, Redfern DR. Accuracy of intraarticular injections for osteoarthritis of the trapeziometacarpal joint. Int J Clin Pract. 2003;57(4):265-266.

9. Sethi PM, Kingston S, Elattrache N. Accuracy of anterior intra-articular injection of the glenohumeral joint. Arthroscopy. 2005;21(1):77-80.

10. McGarry JG, Daruwalla ZJ. The efficacy, accuracy and complications of corticosteroid injections of the knee joint. Knee Surg Sports Traumatol Arthrosc. 2011;19(10):1649-1654.

11. Iagnocco A, Naredo E. Ultrasound-guided corticosteroid injection in rheumatology: accuracy or efficacy? Rheumatology (Oxford). 2010;49(8):1427-1428.

12. Louis LJ. Musculoskeletal ultrasound intervention: principles and advances. Radiol Clin North Am. 2008;46(3):515-533, vi.

13. Epis O, Iagnocco A, Meenagh G, et al. Ultrasound imaging for the rheumatologist. XVI. Ultrasound-guided procedures. Clin Exp Rheumatol. 2008;26(4):515-518.

14. Bain GI, van Riet RT, Gooi C, Ashland N. The long term efficacy of corticosteroid injection into the acromioclavicular joint using a dynamic fluoroscopic method. Int J Shoulder Surg. 2007;1(4):104-107.

15. Balint PV, Kane D, Hunter J, McInnes IB, Field M, Sturrock RD. Ultrasound guided versus conventional joint and soft tissue fluid aspiration in rheumatology practice: a pilot study. $J$ Rheumatol. 2002;29(10):2209-2213.

16. Bisbinas I, Belthur M, Said HG, Green M, Learmonth DJ. Accuracy of needle placement in ACJ injections. Knee Surg Sports Traumatol Arthrosc. 2006;14(8):762-765.

17. Bliddal H. Placement of intra-articular injections verified by mini airarthrography. Ann Rheum Dis. 1999;58(10):641-643.

18. Catalano OA, Manfredi R, Vanzulli A, et al. MR arthrography of the glenohumeral joint: modified posterior approach without imaging guidance. Radiology. 2007;242(2):550-554. 
19. Cunnington J, Marshall N, Hide G, et al. A randomized, double-blind, controlled study of ultrasound-guided corticosteroid injection into the joint of patients with inflammatory arthritis. Arthritis Rheum. 2010;62(7):1862-1869.

20. Curtiss HM, Finnoff JT, Peck E, Hollman J, Muir J, Smith J. Accuracy of ultrasound-guided and palpation-guided knee injections by an experienced and less-experienced injector using a superolateral approach: a cadaveric study. PM R. 2011;3(6):507-515.

21. Im SH, Lee SC, Park YB, Cho SR, Kim JC. Feasibility of sonography for intra-articular injections in the knee through a medial patellar portal. J Ultrasound Med. 2009;28(11):1465-1470.

22. Rutten MJ, Maresch BJ, Jager GJ, de Waal Malefijt MC. Injection of the subacromial-subdeltoid bursa: blind or ultrasound-guided? Acta Orthop. 2007;78(2):254-257.

23. Peck E, Lai JK, Pawlina W, Smith J. Accuracy of ultrasound-guided versus palpation-guided acromioclavicular joint injections: a cadaveric study. PM R. 2010;2(9):817-821.

24. Pichler W, Weinberg AM, Grechenig S, Tesch NP, Heidari N, Grechenig W. Intra-articular injection of the acromioclavicular joint. $J$ Bone Joint Surg Br. 2009;91(12):1638-1640.

25. Sabeti-Aschraf M, Lemmerhofer B, Lang S, et al. Ultrasound guidance improves the accuracy of the acromioclavicular joint infiltration: a prospective randomized study. Knee Surg Sports Traumatol Arthrosc. 2011;19(2):292-295.

26. Bum Park Y, Ah Choi W, Kim YK, Chul Lee S, Hae Lee J. Accuracy of blind versus ultrasound-guided suprapatellar bursal injection. J Clin Ultrasound. 2012;40(1):20-25.

27. Hall S, Buchbinder R. Do imaging methods that guide needle placement improve outcome? Ann Rheum Dis. 2004;63(9):1007-1008.

28. Sibbitt WL Jr, Peisajovich A, Michael AA, et al. Does sonographic needle guidance affect the clinical outcome of intraarticular injections? J Rheumatol. 2009;36(9):1892-1902.
29. Nunez SE, Draeger HT, Rivero DP, Kettwich LG, Sibbitt WL Jr, Bankhurst AD. Reduced pain of intraarticular hyaluronate injection with the reciprocating procedure device. J Clin Rheumatol. 2007;13(1): 16-19.

30. Moorjani GR, Michael AA, Peisajovich A, Park KS, Sibbitt WL Jr, Bankhurst AD. Patient pain and tissue trauma during syringe procedures: a randomized controlled trial. J Rheumatol. 2008;35(6):1124-1129.

31. Sibbitt WL Jr, Band PA, Chavez-Chiang NR, Delea SL, Norton HE, Bankhurst AD. A randomized controlled trial of the cost-effectiveness of ultrasound-guided intraarticular injection of inflammatory arthritis. J Rheumatol. 2011;38(2):252-263.

32. Sibbitt WL Jr, Band PA, Kettwich LG, Chavez-Chiang NR, Delea SL, Bankhurst AD. A randomized controlled trial evaluating the cost-effectiveness of sonographic guidance for intra-articular injection of the osteoarthritic knee. J Clin Rheumatol. 2011;17(8):409-415.

33. Sibbitt W, Kettwich L, Band P, et al. Does ultrasound guidance improve the outcomes of arthrocentesis and corticosteroid injection of the knee? Scand J Rheumatol. 2012;41(1):66-72.

34. Daley EL, Bajaj S, Bisson LJ, Cole BJ. Improving injection accuracy of the elbow, knee, and shoulder: does injection site and imaging make a difference? A systematic review. Am J Sports Med. 2011;39(3): 656-662.

35. Bellamy N, Campbell J, Robinson V, Gee T, Bourne R, Wells G. Viscosupplementation for the treatment of osteoarthritis of the knee. Cochrane Database Syst Rev. 2006;2:CD005321.

36. Bannuru RR, Natov NS, Dasi UR, Schmid CH, McAlindon TE. Therapeutic trajectory following intra-articular hyaluronic acid injection in knee osteoarthritis - meta-analysis. Osteoarthritis Cartilage. 2011;19(6):611-619.

37. Samuels J, Abramson SB, Kaeley GS. The use of musculoskeletal ultrasound by rheumatologists in the United States. Bull NYU Hosp Jt Dis. 2010;68(4):292-298.
Clinical Interventions in Aging

\section{Publish your work in this journal}

Clinical Interventions in Aging is an international, peer-reviewed journal focusing on evidence-based reports on the value or lack thereof of treatments intended to prevent or delay the onset of maladaptive correlates of aging in human beings. This journal is indexed on PubMed Central, MedLine, the American Chemical Society's 'Chemical Abstracts Ser-

\section{Dovepress}

vice' (CAS), Scopus and the Elsevier Bibliographic databases. The manuscript management system is completely online and includes a very quick and fair peer-review system, which is all easy to use. Visit http://www.dovepress.com/testimonials.php to read real quotes from published authors. 